\title{
Taylor Rule And Inflation Targeting: Evidence From New Zealand
}

\author{
Zied Ftiti, (Email: ftiti@gate.cnrs.fr), University of Lyon, France \& University of Tunis, Tunisia
}

\begin{abstract}
New Zealand has the longest experience in inflation targeting. This policy was announced on March $4^{\text {th }} 1989$ and was put into action on February $1^{\text {st }}$ 1990. In addition, New Zealand has the most clearly defined target and policy framework for achieving it. Thus, in order to conduct this policy, Taylor (1993a) defined an instrument, which is called «Taylor rule». This rule applied to the US economy becomes a reference for all subsequent studies, which look for the rule or the instruments to conduct an inflation targeting policy. The New Zealand reserve bank (NZRB) has focused rather more strongly than the Federal Reserve Bank (FED) on price stability. So, we show that the Taylor rule with standard parameter didn't reflect the behaviours of the NZRB. In this paper, we try to find the best instrument, which reflects the behaviour of the RBNZ. The methodology of our paper consists in comparing some rules, like Traditional Taylor rule (TTR) and some style rules, which are different. Our methodology consists to select the best rule using both the Fisher test and the information criteria. The estimation methods depend on the result of the exogeneity, autocorrelation and heteroscedasticity. We find three important results. We show that the TTR with standard parameter used in the US doesn't describe New Zealand monetary policy. Therefore, we show that the best rule, which reflects the behaviour of the NZRB, is a forward-looking rule. Finally, an important result, which we interpreted with some discretion, that the exchange rate must be included in the rule.
\end{abstract}

Keywords: Taylor rule, inflation Targeting, monetary policy, exchange rate, smoother interest rate, ForwardLooking, New Zealand.

\section{INTRODUCTION}

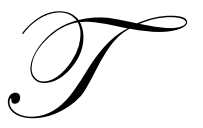

he instability of prices is a source of uncertainty. It distorts the economic decision process and causes an economic instability. Generally, this instability results from inflation. Liquidity excess is its major origin. By this we mean that there is too much currency for enough goods. If the currency in circulation increases, the private agents raise their goods and services demanding. If it is not accompanied by an increase in production, the prices go up. Thus, to handle this problem, many researchers ask on variables that we must act to reach the stability of prices. The majority of studies have been concentrated on the exchange rate because it presents a transmission channel of the external shocks. Thus, they used a fixed exchange rate to control inflation. But, this strategy is not efficient and it is not applicable because the instability growth of capital follows during the end of seventies ${ }^{1}$. Even, when some central banks adopted a flexible exchange rate (in the beginning of eighties decades), they didn't control efficiently inflation. Then, the repeated failure and the persistent instability of the relationship between the monetary growth and inflation pushed the majority of them to cease targeting the monetary aggregates during the Eighties. It will be more necessary to find a best policy, which control efficiently the inflation and ensure the price stability.

At the end of the Eighties, many industrialized countries as well as emergent countries started to target inflation. Hence, a new economic policy named "inflation targeting" has appeared. This policy is a decision rule, which aims to increase the transparency around the monetary policy followed by a central bank. It aims at

\footnotetext{
${ }^{1}$ The impractical of fixed exchange rate policy was illustrated by the crisis in the Nineties.
} 
announcing the target level that permits to point the economic agent's anticipation. It tries to make its action more foreseeable and readable by the other agents and thus to reduce volatility on markets. Clearly, this rule is based on a flexible and pragmatic vision of monetary policy.

New Zealand was the first country to adopt this economic policy in March 1989 and has applied it since February 1990. Today, several countries applied inflation targeting policy. But only eighteen of them adopted it in a credible and clear way ${ }^{2}$. These countries respected the three main policy inflation targeting assumptions: They start explicitly to attain the inflation goal predefined. These countries are characterized by operational independence from the government because the central bank has the full autonomy to pursue its inflation goal. Then, they announced the inflation objective (The inflation Target) to the public to ensure the credibility of their monetary policies.

The inflation targeting policy set it action on inflation. Indeed, when inflation deviates from its objective, the central bank uses a monetary policy instruments to align the expected inflation to the objective. Then, several researches were undertaken to determine the adequate instrument to conduct this policy. Taylor (1993b) is the pioneer who proposed an instrument to control the monetary policy for the federal reserve bank (FED) of the United States called "Taylor Rule". This rule is a simple instrument of the interest rate linking the nominal interest rate to some economic variables; usually inflation and the real output. In the view of the objectives adopted by the FED, which consist on duality between inflation stability and economic stability, Taylor (1993b) associated two coefficients equal to 0.5 for both the inflation gap and the output gap. Because of its simplicity and its capacity to reduce the econometric investigations, this rule was gradually imposed as a reference rule for the majority of empirical work, although its initial vocation was more descriptive than normative.

On a more elaborated mode, other normative rules, generally qualified by optimal, can be derived from small macroeconomic models. These models included an equation specifying the Central Bank Loss Function and are supposed to represent the relative importance of the goals that it pursues. These rules, which are qualified by optimal, are called Central Banks Reactions Functions. They differ from a country to another and from a period to another within the same country. Svenson (1997) shows that more complex rules can be more effective to achieve the policy goals. He said, "The style Taylor rule are very optimal”.

The Traditional Taylor rule (TTR) has been criticized for several points. For example, some researchers said that the TTR omits some keys variables. Other said that this rule is not operational. Indeed, Mayes (2000a) and McCallum (1993) note that this type of function (i.e. in function of current data) is not operational because it needs information that actually policy-makers don't have. In order to make them realizable and effective, the majority of researchers and economists suggest replacing these variables by their forecasts, by taking into account the central bank objectives.

The objective of this paper is to verify the efficiency of TTR. In other words, we try to determine the nature of the rule that reflects the behaviour of the RBNZ under inflation targeting during the period from 1990 to 2005 . In other words, we try to find out which variables the best rule must include to conduct the monetary policy in the case of inflation targeting. The second objective of this paper is to determine whether the RBNZ takes into account the exchange rate fluctuations to conduct its inflation targeting policy. Our choice of New Zealand among several countries, which adopted the inflation targeting policy, is made for several reasons. First, New Zealand is the first country, which adopted such policy. So, it has the greatest experience of this central bank in this policy. In addition, the NZRB is the single central bank, which published its expected inflation rate for a significant number of years.

The paper is organized as follows. Section 2 is a literature review on the traditional Taylor rule. Section 3 contains the source of the data and the theoretical methodology followed in this paper. Section 4 represents the evolution of the principal economic variables, which represent the economic change since 1990, date of the implementation of this policy. Section 5 reports the econometric analysis. Last section encompasses the conclusion.

\footnotetext{
${ }^{2}$ The eighteen countries which adopted correctly the inflation targeting policy are: New Zealand, Canada, UK, Australia, Czech Republic, Israel, Brazil, Poland, Korea, Colombia, South Africa, Hungary, Thailand, Iceland, Mexico, and Norway.
} 


\section{I- LITERATURE REVIEW}

Several researchers are interested in the monetary policies rules. They are characterized by a debate between some economic schools. Two concepts underlie this debate: the neutral currency and the inflationary bias. The neutral currency is an old idea that was reasserted by theorists of the real cycle. They consider that, although the currency is not neutral in the short run, it will have no effect in the long run. Thus, the monetary policy must concentrate on economy anchoring, by defining, for example, a maximum objective of inflation. Then, the objective of economic stabilisation becomes secondary. On the other hand, Barro and Gorden (1983) concluded that, "In discretionary monetary policies, policy-makers are always suspected by the private agents who wanted to make surprised inflation to stimulate the activity". As a consequence, these policies are not very credible, which creates the inflationary bias of the discretionary policy. Thus, Rogoff (1985) contemplates a solution to reduce the inflationary bias and to finish with this lack of credibility. This solution consists in supposing some active behaviour rules for the monetary authorities. These rules provide some advantages that are flexible and allow the immutable behaviour of the authorities' engagement, which preserves them from the temporary inconsistency and inflationary bias. Indeed, Rogoff (1985) is the first to have evoked the active rules, but Taylor is the first who formulated this rule in function of the short-run interest rate.

In 1993, John Taylor developed a simple interest rate rule for the choice and the evaluation of the instruments that conducts the monetary policy. This rule has been known under the name of the Taylor rule. It can be used both for the evaluation of the later policies and also to determine those of the future. It recommended a rise (fall) of the interest rate when the inflation rate is above (bellow: case of recession) its targets level. In fact, the monetary policy instrument presented by Taylor suggests that the central bank linked the short run interest rate with inflation and the output. More precisely, this rule shows that the nominal interest rate is a function of the inflation rate plus the equilibrium real interest rate plus two deviations that have the same coefficient, and both equal to 0.5 . The rule suggested by Taylor is as follows:

$$
i=\pi+r^{*}+a_{Y} Y_{G}+a_{\pi}\left(\pi-\pi^{*}\right)
$$

According to Taylor (1993b), $a_{\pi}=a_{Y}=0.5$ are weighting coefficients.

Where i: Interest rate, $\pi$ : inflation rate, $Y_{G}$ : output gap, $r^{*}$ : equilibrium interest rate. $\pi *$ : Inflation target level.

This rule presents an extension of the studies of Bryan et.al (1993). They consider the monetary policy rule, which consists in the interest rate deviation from its equilibrium level as a linear function of the deviation of a key variable named $\mathrm{Z}$ from its target level. This is given by: $i-i^{*}=\theta\left(Z-Z^{*}\right)$

All the studies converge towards two keys variables as being good indicators of the economy. These studies require targeting the sum of the price level and the output. This implies to target the money-income, i.e. nominal income: $i-i^{*}=\theta_{\pi}\left(\pi-\pi^{*}\right)+\theta_{q}\left(q-q^{*}\right)$

Thus, starting from these studies, Taylor forms its famous rule. The monetary policy instrument presented by Taylor considers that the short run interest rate is a function of two observed quantities: the inflation rate $(\pi)$ and deviation from real output $(y)$. Four components of the model are treated as constants: a pair of adjustment parameters $h$, the adjustment parameter that applies to inflation, and $g$, the adjustment parameter that applies to output, the equilibrium real rate of interest $\left(r^{f}\right)$, and optimal level of inflation $\left(\pi^{*}\right)$. The deviation from real potential output $(y)$ is simply the difference between potential GDP and actual GDP ${ }^{3}$.

The two adjustment factors can incorporate at the same time short-run and long-term objectives. The inflation gap adjustment factor incorporates long run objective for the central bank (price stability). The output gap adjustment factor is based on the idea that the short run monetary policy is useful to avoid the cyclic changes

\footnotetext{
${ }^{3}$ Kevin Corder. p.5 "Taylor Rule and monetary Policies"
} 
(economic stability). The main goal is to allow output to have a durable growth around its potential trend. The output gap adjustment factor can represent another aspect of economic policy. Indeed, some analysts regard it as an indicator or a signal for future events. According to this idea, a positive output gap is an indicator of increasing future inflation. Thus, the interest rate rule, which reflects an adjustment output gap, can correspond to designated political action to hinder rises of expected inflation.

Starting from these two-parameter contributions, we can conclude that Taylor rule aims at a major policy of price stability. Theoretically, the Taylor rule has been refined by several contributions, such as, those by Svenson (1997), which shows that this rule can appear as the solution of optimal control schedule under inflation targeting. Thus the majority of the countries that chose inflation-targeting policy have adopted Taylor type rule to conduct their monetary policy. Taylor (1993 b) did not estimate the rule but he imposed some assumptions for this linear model. The target of inflation is supposed to be equal to $2 \%$ and the equilibrium real interest rate is supposed to be equal to $2 \%$. Taylor considered his rule as being very simple (reducing enormously the econometric investigations). But at the same time, it is able to capture the essential elements of the systems that the central banks predicted and to link the political instruments to the actual economic conditions. Then, this rule is an adequate mean for the control of economic policy. But the question to estimate this rule instead of adopting assumptions becomes the first literature preoccupation and causes some theoretical and practical problems. To estimate rule, we must determine some variables that are unobservable like the potential output, inflation rate and neutral interest rate. Many studies are undertaken to identify the best econometric method allowing an optimal estimation. Among potential output measurements adopted in some studies, we find the HP filter, the polynomial tendencies (quadratic or cubic) and model with unobservable component (kalman filter). Moreover, there are several alternatives to determine inflation (such as the use of the GDP deflator or the use of the consumer price index). Indeed, Gerdesmeier and Roffia (2003) in Euro area reached many measurements of output and inflation to determine the optimal monetary policy.

The problem with this approach is that there is no consensus about the appropriate instrument or target or about what variables (and what lags) must be included in the right hand side of the reaction function. In fact, the difference between economic structures of the various countries necessarily leads to a difference in instruments that conduct monetary policy. Indeed, some countries response to the exchange rate fluctuations. Several of them seek to diffuse some credibility in the objective to ensure an economic stability by adopting a partial interest rate adjustment. Then, we cannot apply a standard rule for all the countries. But this rule must be adapted to the economic structure for each country by including the key variables associated with each economy. Thus, emerge the concept of "Taylor type rule". There are some difference between TTR and a type Taylor rule, which appear in various points:

- $\quad$ The first difference between the TTR and the specifications for type Taylor concerned the timing of the economic variables on which the short run interest rate depends. Indeed, the Taylor rule recommends that the interest rate must be a function of contemporary values of the output gap and the inflation during the four last quarters. Others works, used the expected values of inflation rate and output.

- A second difference concerns the adjustment factors of the inflation deviation and the output gap. These coefficients represent the economic policy dynamism to the output deviation from its potential level and those of the inflation of its target. In the TTR, considering the duality of objectives of the price stability and economic stability adopted by FED, the coefficients of the inflation gap and the output gap are supposed to be equal to 0.5. This explains the lack of consensus in economy on the weight associated to these coefficients. The researchers suggest that these coefficients must be estimated for each country because of the difference in their objectives.

- $\quad$ Another difference is in the using of the smoothing interest rate policy. Indeed, Taylor (1993) didn't take into account this policy but other researchers such as Orphanides (1997) and Clarida, Gali, and Gertler (1999), suggest that FED tends to smooth its interest rate. The purpose of this behaviour is to assure some degree of credibility in its monetary policy and to lead economic stability.

- $\quad$ The Taylor type rules adopt some different measures from those of Taylor in the determination of the output and inflation. There exists also a very important difference that arises from the interest rate that must

\footnotetext{
${ }^{4}$ Kozicki (1999): is the first who had adopted the "Taylor Type rule" word.
} 
be taken as explanatory variables. Indeed Taylor (1993b) picks up the directing rate aimed by the federal funds rate. Whereas, other researches, such as in Lubik and Shorfeidle (2005), adopt the discount rate or the money market rate in 3 months.

Considering the effectiveness and the simplicity of this rule and its objectives, many countries adopted it with a principal goal to follow the inflation targeting policy in order to reduce the pressure and the increase in inflation.

Although, the traditional Taylor rule is the starting point for studies aiming to determine the optimal instrument in the case of inflation-targeting policy. Several economists are interested in estimating Taylor rule under its traditional version to conclude whether this rule reflects the objectives of such central banks. Indeed, New Zealand is one of these countries, which chooses an inflation targeting policy and has a priority objective of price stability. For this country, many studies are undertaken. Among them, one carried out by Huang, Margaritis and Mayes (2000) and another by Plantier and Scrimgoeus (2002). In the last study, authors assessed the Taylor rule under its traditional version for New Zealand on the period from 1988 to $2001^{5}$. They adopted two different alternatives to be taken into account for three different approaches. A first approach consists in estimating a specification with the ordinary least squares (OLS) and recursive ordinary least square (ROLS). With this approach, the authors conclude that the output gap response is equal to 0.4 and that of the inflation gap is equal to 0.62 (the equilibrium interest rate is equal to $5 \%$. It is considered as constant value). The second approach adopted by the authors, is to determine the equilibrium interest rate by a state space model. In this case, the estimation leads to 0.4 for output gap response and 0.72 for inflation response. These results were conforming to RBNZ objectives that give more priority to the price stability than to the economic stability. Huang, Margaritis and Mayes (2000) consider that the equilibrium real interest rate is equals to the average difference between the nominal interest rate and the inflation target rate. Moreover, they adopt a constant inflation target that is equal to 1.5 all along the period of study.

The traditional Taylor rule does not claim to provide a reference norm to the interest rate in theory but rather to describe, in a synthetic way, how the central bank reacts to the fluctuations of some economical key variables during a given period. These variables are the inflation gap and the output gap. But other variables prove to be relevant such as the one lag of the interest rate, the exchange rate and the surplus liquidity. Then, several studies were interested to determine an adequate reaction function from type Taylor by including the variables that provide additional information. The transition to estimate these reaction functions was beheld for several reasons. These functions contemplate to change the monetary policy instrument of the central bank. Then, they present a major element in evaluating the policies of central banks and the economic shocks effect. Thus, several studies estimated the various reaction function specifications to many central banks that adopted an inflation targeting. For example Huang, Margaritis and Mayes (2000) and Gerdesmeier and Roffia (2003) estimated a reaction function of Taylor type. They apply it to the actual data of inflation and output gap. Moreover, they incorporated a partial adjustment interest rate. Thus, the equation has the following form:

$$
i_{t}=\rho i_{t-1}+(1-\rho)\left[a_{0}+\alpha \pi_{t}+\beta Y_{g}\right]+u_{t}
$$

However, the recent literature has been more interested in the Forward-Looking Taylor rule. According to Mayes (2000b) the emergence of this concept does not constitute a surprise. The general traditional Taylor rule suggests that the interest rate must be granted to output gap and to inflation on the current data, but this links information that is not currently available; that's why it is never relevant to follow this type of rule. To make them realizable and effective, the majority of the researchers and economists suggest to replace these variables by theirs anticipated values. This can be possible to connect the available information. So, recent researches estimated these Forward-looking rules. Gresdesmeir and Roffia (2003), Caputo and Liendio (2005) have estimated a ForwardLooking rule respectively in euro area and Chilean economy. They conclude that the Forward-Looking rule is better than the other rule to reflect the behavior of central bank, which adopted inflation-targeting policy.

\footnotetext{
${ }^{5}$ By referring Plantier and Scrimgoeus (2002), the interest rate, since 1988, is not stationary I (1) and the other variables are stationeries I(0). These authors suggest not to take the equilibrium interest rate as constant value.
} 
In the last decade of 1990's, a new literature criticizes the Taylor rule. It said that Taylor rule forgets some keys variables that have an important role in an open economy. The key variable, that interested the majority of the economists, is the exchange rate. The basic question in the recent literature is: what is the role of exchange rate in the monetary policy rule?

The pioneers' studies targeting this question are those of Ball (1999), Svenson (2000) and Taylor (1999), (2000) and (2001). In these studies the authors use the following function: $i_{t}=f \pi_{t}+g * y_{t}+h_{0} e_{t}+h_{1} e_{t-1}$ where e: exchange rate

The interest of these studies is to see whether the coefficients $h_{0}$ and $h_{1}$ are not null. Svenson (1999) leads to $h_{0}=0.45$, however Taylor (2001) reaches to $h_{0}=-0.25$ and $h_{1}=0.25$, in the case of the European central bank (ECB). Taylor (2001) shows that some countries cannot react directly to the exchange rate deviation ( $h_{0}$ and $h_{1}$ are null) but their reactions are indirect. In this last case, the role of exchange rate is explained by the indirect monetary transmission mechanism, evoked by Obstfeld and Rogoff (1995). They suggest that an exchange rate appreciation, in the case of an open economy, has two effects: It decreases the real output by the substitution effect and decreases inflation considering the imported goods prices. Moreover, inflation can be reduced by the decline of the real output. These effects will take place with lags: it is the inertia of the monetary transmission mechanism. Considering this lags, the fall of inflation and output will introduce the fall of the future interest rate. In this context, Lubick and Shorfheide (2005) and Caputo and Liendo (2005) had evaluated the effect of exchange rate on monetary policy in inflation targeting. Lubick and Shorfheide (2005) estimated this function for four developed countries, News Zealand, Australia, England and Canada. They limited the application of this function to emergent markets and conclude that the central banks of Canada and England react to the exchange rate fluctuation contrary to the central banks of New Zealand and Australia. Caputo and Liendo (2005) test these same problems on the Chilean economy using the function above. They conclude that it is very interesting for the Chilean economy (emergent market) to react to the inflation deviation and to the output fluctuation, and that there is no advantage to react to the exchange rate fluctuation. According to these studies, the absence of explicit response to the exchange rate does not imply that this variable is not involved in the decision-making process, but the openness changes the structure of the economy and the reaction of the monetary policy. In this same context, Gerdesmeier and Roffia (2003) estimate a Forward-Looking reaction function by including variables that reflects the exchange rate applied to data of the euro area. They conclude that the monetary policy followed by these countries explicitly responds to the exchange rate fluctuation.

The originality of our paper is in the methodology that we are followed to show which rule (TTR or type Taylor rule) reflects in better way the NZRB behaviors under inflation targeting. In deed, we start by estimate the TTR after that we estimate some specific Taylor type rule and we compare them. We conclude in the first step from our two first rules that the Traditional Taylor rule with its standard parameter didn't reflect the NZRB behaviors. Then, the comparison between the estimated types Taylor rule show some theoretical result like the adoption of the smoothing interest rate and we proof econometrically the necessity of the forecast inflation targeting. This the difference for paper from other, because the studies before-mentioned are based on some criticized and estimated only either a TTR or the type traditional Taylor rule and put their conclusion.

\section{II- METHODOLOGY AND DATA}

\section{$1 \quad$ Methodology}

Our methodology consists to start by describing the business cycle of New Zealand from 1990 to 2005, to see the change behind the using of inflation targeting regime. After that, we use an empirical approach to determine the optimal monetary policy that describes the behaviour of the NZRB.

In the empirical approach we start by estimating the Traditional Taylor rule. Then, we try to estimate the other specification, which differs from the TTR. Indeed, we estimate two types of reaction functions, one under a 
static version and the other under a dynamic version. This last equation differs from the first one by the introduction of the smoothing interest rate ${ }^{6}$. It consists in checking if the RBNZ adjusts gradually its interest rate in order to preserve credibility for its policy. Thus, we will compare these two functions using the criteria of Akaike and Schwarz to know, which is optimal model reflect the behaviour of the RBNZ. In this case, the dynamic rule is given by:

$$
R_{t}=\rho R_{t-1}+(1-\rho)\left[R^{*}+\pi_{t}+\alpha\left(\pi_{t}-\pi_{t}^{*}\right)+\beta\left(Y_{t}-Y_{t}^{*}\right)\right]+u_{t}
$$

Where, i: 3month money market rate $\rho$ : The adjustment coefficient of interest rate.

Then, we will consider the critical advanced by McCallum (1993), which notes that the traditional Taylor rule will not be operational because it needs information, which is not available for the policies makers. Thereby it is necessary to substitute the actual inflation rate and the output data by their forecasts. In this case, we come to estimate the Forward-Looking Taylor rule. We adopt the specification of Lubik and Schorfeide (2005), which is, applied to News Zealand, Australia, Canada and England. The specification is given by:

$$
i_{t}=\rho * i_{t-1}+(1-\rho)\left[\alpha * E\left(\pi_{t}\right)+\beta\left(Y_{t}-\bar{Y}\right)\right]+\varepsilon_{t}
$$

In the end, we try to verify if the RBNZ responds explicitly to the exchange rate fluctuation. Thus, we adopt the lubik and Schorfeide (2005) specification, which appreciates the role of exchange rate inside monetary policy, followed by the New Zealand, Australia, England and Canada. In this case the rule is given by:

$$
R_{t}=\rho R_{t-1}+(1-\rho)\left[\alpha\left(\pi_{t+1}\right)+\beta\left(Y-Y^{*}\right)+\gamma\left(e_{t}-e_{t-1}\right)\right]+u_{t}
$$

\section{Data}

In this paper, we are adopting quarterly data used several times in other studies. The choice for this frequency rather than the monthly one does not decrease the study relevance given that the policy makers aim to a medium-term objective of price stability. The data is collected from the $I M F$ for the first quarter of 1989 to last quarter of 2005. The period of estimation corresponds to the beginning of an inflation targeting policy in New Zealand. The variables are: the 90-day interest rate money market, gross domestic product (GDP), and real exchange rate. The other variables are collected from $R B N Z$ such as: the consumer price index (CPIX) excluding the costs of credit services, the inflation target and the expected inflation rate which are published by the RBNZ. However, in our study we determine some unobservable variables such as equilibrium interest rate, output gap and inflation rate.

a-

\section{The output gap}

In all cases, the output gap is expressed as a percent of potential real GDP, calculated by multiplying 100 times the natural logarithm of the ratio of real GDP to an estimate of potential real GDP (Kozicki 1999). This allows us to detect the effects of internal and external shocks on the economic activity and through aggregate demand components. The majority of the studies, in this context use the following function to calculate the output gap:

\section{outputgap $=100 *$ Ln(outputreel / estimationdel'outptutpotentiel )}

In the macroeconomic literature, the potential output had been defined as the realizable production without increased inflation beyond its actual level. It is the result of a normal oscillation of potential economic supply. It is an unobservable variable that will be determined on this study by the filtering method of Hodrick and Prescott (HP Filter). This is a good estimation method because it minimizes the output fluctuation around its trend. By definition, if we apply the HP Filter to determine the output gap we adopt a stationary series.

\footnotetext{
${ }^{6}$ smoothing interest rate: the interest rate was adjusted to the average weighted of the desired interest (t) rate and the average weighted of last realised interest rate.
} 


\section{b- Inflation}

Some studies analysing the monetary policy determine the inflation rate as the percentage of CPIX annual variation $^{7}$. The function that determines the inflation rate is given by:

$I N F_{t}=100 *\left[\left(C P I_{t}-C P I_{t-4}\right) / C P I_{t}\right] \quad$ If we apply the augmented Ducky-Fuller test $(A D F)$, we conclude that the inflation rate is stationary during the period from 1990 to 2005.

c- $\quad$ The real equilibrium interest rate

In practice, the definition of the real neutral interest rate presents more difficulties than in concept. In the original model of Taylor, the real equilibrium interest rate is fixed at $2 \%$. In fact, the macroeconomic literature offers various approaches to calculate this rate:

- $\quad$ Some authors adopt the approach of a constant value: It is equal to the average difference between the nominal interest rate and the inflation target rate. Kozicki (1999) and Smets (1998) adopt this approach to calculate the neutral real interest rate for New Zealand. They conclude that it is equal to $4,98 \% \approx 5 \%$. It is the same approach adopted by Huang, Margaritis and Mayes (2000) for New Zealand.

- $\quad$ By referring to the neo-classic growth theory, the real neutral interest rate is equal to the economic potential growth, i.e. the maintainable growth without excessive inflation.

In our study, we adopt the first approach to determine the neutral real interest rate. With our data we find that $\bar{r}=5 \%$ for New Zealand during the period from 1990 to 2005. We apply the ADF test for the other variables such as the 3-months interest rate money market and the exchange rate fluctuation. We conclude that these series are stationary. We apply the Augmented Dicky Fuller test to test the stationarity of data. The result is that all the variables are stationary.

\section{Data Analysis}

Before estimating the best Taylor rule followed by the RBNZ, it is useful to briefly review the broad macroeconomic characteristics of the 1990s.

A- $\quad$ Output

Figure 1: The cycle GDP growth from 1990 to 2005 in New Zealand

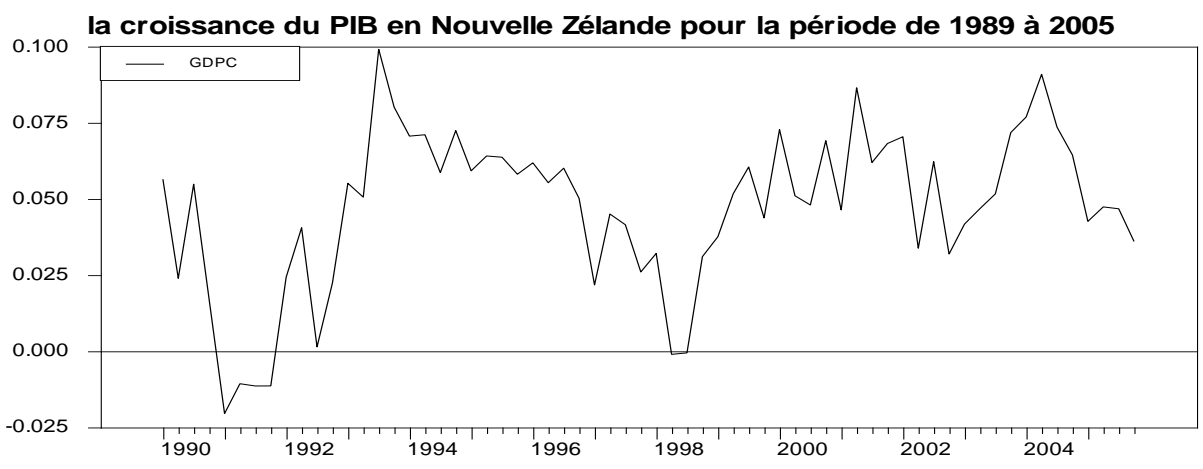

${ }^{7}$ CPIX: is the CPI excluding the cost of credits services. 
Figure 1 presents the cycle in GDP growth over the 1990s. There was a significant recession in the early part of the decade, followed by a strong boom in the mid-1990s. After that, there was a gradual slowing in growth, which conducts to a small contraction in GDP in the first two quarters of 1998. Then, GDP accelerated quite quickly out of through before returning to more moderated growth rates. A boom followed this period in the 2004. Then, GDP has a period of stability during 2005.

This cycle can economically be explained. The expansion in output from 1991 to 1997 that the New Zealand experienced have lasted two years longer than the previous two expansions experienced in New Zealand. In other words, it was strong relative to New Zealand's history and contemporaneous OECD country experiences. This expansion was driven both, by the flow on effects of structural reform undertaken in the late 1980s, and more traditional business cycle drivers. These drivers included robust world demand condition, high commodity prices for the New Zealand's exports, strong net inward migration flows, high level of business, high level investment expenditures, and later, expansionary fiscal policy. The amount of exportation is around 30 percent of GDP. The East Asia accounted for over 40 percent of New Zealand's exports. Then, the East Asian crisis of 1997 significantly affected both the volume and value of New Zealand's exports, which causes the recession at the beginning of 1998 as showed by Figure1. From 1998 to 2002, RBNZ has adopted a new monetary policy MCI "monetary condition index", this policy takes into account the exchange rate deviation to neutralize the external shock effects. Then, in this period, the GDP has a moderate rate growth. In 2004, we observe a boom in GDP rate growth, then a stable growth rate.

\section{B- Inflation}

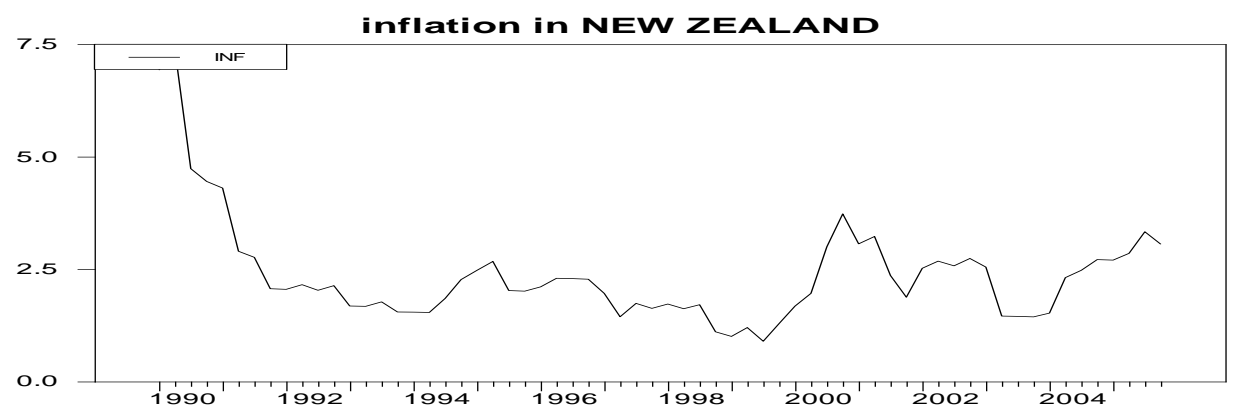

Figure 2: Inflation in New Zealand from 1990 to 2005 in New Zealand

According to figure2, it is clear that the inflation rate has a high value and volatility in the late of 1988s. At the beginning of 1990, the inflation rate becomes more stable and had a low value. Since achieving the 0 to $2 \%$ inflation target in 1991, monetary policy can be credited with having successfully anchored the inflation rate over the remainder of decade. From 1991, as indicated in figure 2, the inflation rate remains typically between 1 per cent and 2.5 per cent. There were two breaches of the top of the (then 0 to 2 per cent) inflation target band: in the June quarter of 1995 and through 1996. However, the Bank's measure of underlying inflation never came close to breaching the lower edge of the target, and indeed never fell into the bottom half of the then 0 to 2 per cent target band. Subsequent to a number of adverse shocks in 1998 CPIX inflation fell to a trough of about 1 per cent by late 1998. In the late 1999, the inflation rate starts to increase. This can be explained by the three large negative shocks ${ }^{8}$. After a policy target agreement in 2002, the inflation rate becomes more stable.

\footnotetext{
${ }^{8}$ The three large negative shocks are: The East Asian crisis of 1997, then the supply side agricultural production contraction and the change in the national immigration.
} 


\section{C- 90 Days Interest Rate}

Fig3: The interest rate path from 1990 to 2005 in New Zealand

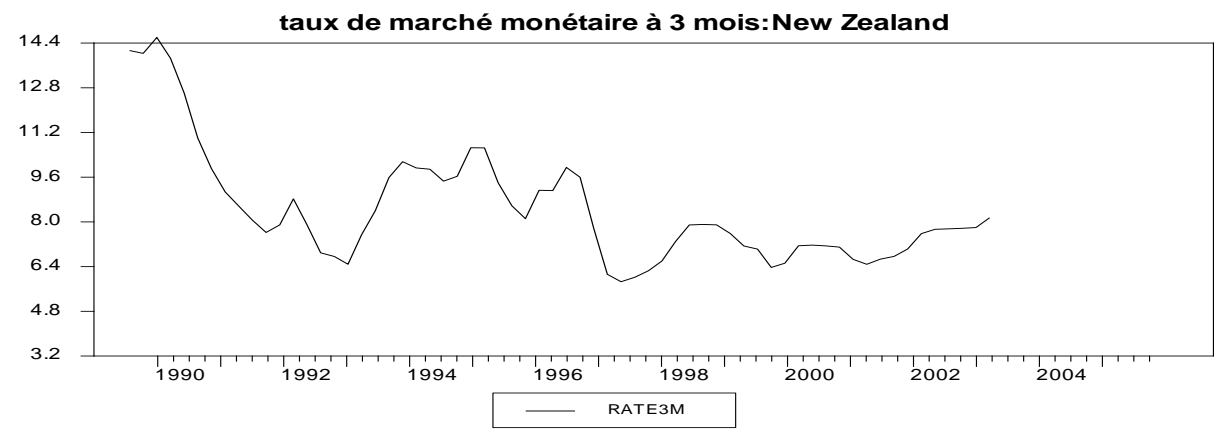

According to figure 3, the path of the interest rates through the 1990s featured by five humps: 1990/94, 1994/95, 1996, 1997/99 and 1999/2005.

From 1990 to 1992 , we observe that the interest rate decreases dramatically (from $14,4 \%$ to $5 \%$ ). It is the impact of the adoption of inflation targeting policy. From the late of 1994 to early 1997, 90-day rates in New Zealand averaged about 9 per cent. It was a response to strong inflation pressures. After that, in 1994, the interest rate rises from $5 \%$ to $10 \%$. This can be explaining by the monetary tightening, and the general attractiveness of New Zealand as a destination of international capital. The interest rate reaches to a pick in 1996 of $10 \%$, after that it starts to decrease.

From 1997 to 1999, the interest rate deceases at 4\%. This is explained by the policy target agreement (PTA) announcement in 1996. From the beginning of 1999 to 2005, the interest rate becomes more stable around 5\%.

D-

Exchange rate deviation

Fig4: the effective exchange rate from 1990 to 2005 in New Zealand

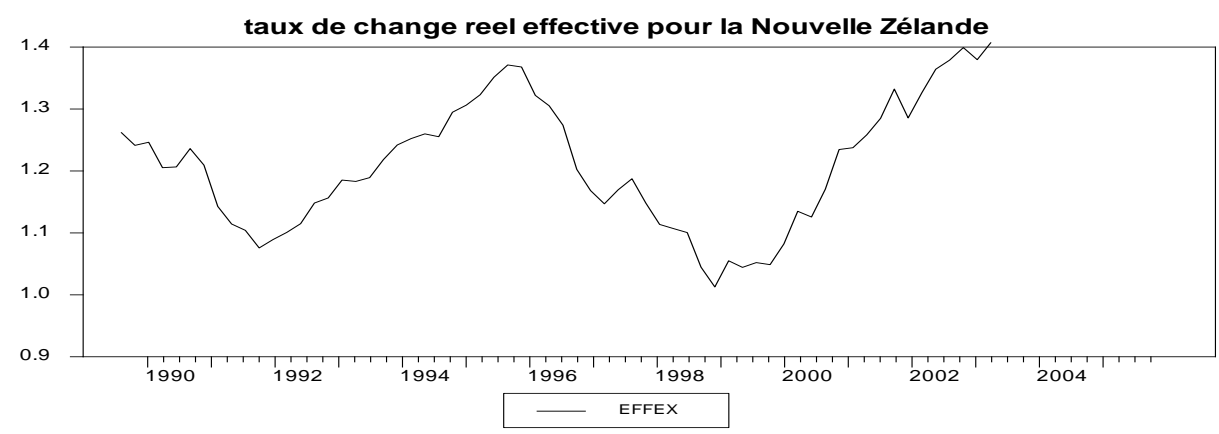

According to figure 4, we observe a decreasing in the deviation of the exchange rate from 1990 to 1993 , then an appreciation around $30 \%$ between the first quarter of 1993 and the first quarter of 1997. This appreciation can be explained as a result of the interest rate increasing in the same period to handle the high inflation. After that, it depreciated by around 30 per cent. Finally, it increased.

Then, after analysing some key macroeconomic indicators, we remark a change in the economic behaviour of New Zealand since 1990. In fact, the interest rate and inflation rate decreased to ensure some economic stability. 
Output has been more stable and moderate growth rate. Thus, these economic changes reflect the economic behaviour fixed by RBNZ with the policy of inflation targeting.

According to Huang, Margaritis and Mayes (2000), the NZRB takes two principal objectives in its monetary policy. The price stabilities and economic stability, but with more preoccupation for price stabilities than the second objective. Thus, because of the difference in objectives for each country, we must determine the optimal monetary policy that describes the best RBNZ behaviour's.

\section{III- EMPIRICAL ANALYSIS}

\section{1- Traditional Taylor Rule Estimation}

In this part, we will estimate the Traditional Taylor rule for New Zealand during the period from 1990 to 2005. The RBNZ adopt the 3-months interest rate money market to conduct its monetary policy. The RBNZ announces that it needs money market condition by specification of the 3-month money market rate, which is coherent with the objective of price stability. Moreover, this rate can be melt with exchange rate and allowed to lead to any market rate by a quantitative control on overnight financial market. That's why to set up its price stability policy and then its inflation targeting policy, we adopt a 3 -months money market rate. The traditional Taylor rule $t$ is given by [1]

OlS did the estimation after verifying the six assumptions necessary to apply this method. We use also the ADF test to look for stationary and the Hausman test to look for endogenity. We conclude that all variable for the first specification are stationeries and exogenous.

The estimation results of this model are as follows: the inflation gap coefficient is equal to 0.77 , which imply $\mathbf{1 . 7 7}$ for inflation rate coefficients and $\mathbf{0 . 2 4}$ for output gap coefficient. These coefficients are statistically significant. The Durbin Watson statistic is equal $\mathbf{1 . 9}$ and then we note the absence of serial correlation. According to this estimation result, New Zealand has granted a much higher weight to inflation rate than to output gap. These two coefficients are significant, but it is important to indicate that the coefficient of inflation deviation is more significant than the output gap one. This implies that New Zealand accords more priority to the price stability than to the economic stability. It is conforming to RBNZ's objectives. Thus, we confirm the assumption that New Zealand leads an inflation targeting policy with a relatively weaker output gap weight than 0.5 . However, the FED accepts an equal coefficient (0.5) to output gap and inflation deviation. This is the result of its dual objectives for both price and economic stability. However, the RBNZ is more concerned by price stability. That's why we find a higher coefficient for inflation deviation than for the output gap.

Our results are almost similar to those of L. Plantier and D.Scrimgeour (2002), who estimate the traditional Taylor rule in New Zealand with OLS method and find an inflation deviation coefficient equal to $\mathbf{0 . 8}$ and $\mathbf{0 . 4}$ for the output gap coefficient.

The adjustment coefficient $R^{2}$ that measures the variation degree of short-run interest rate is weak. We conclude that this rule does not have an important explanatory power because it may be due to a lack of some key variables that provide additional information.

The initial vocation of Taylor rule is more descriptive than normative. Most of the time, this rule is not estimated but it is based on calibrations or assumptions such as in Taylor (1993a) and ball (1999). In a more elaborated mode, other normative rules, generally qualified by optimal, can be derived from small macroeconomic models as the specifying central bank loss function. In other word, it is supposed to represent the relative important objectives followed by the RBNZ. These rules are called the reaction functions, which are derived from the traditional Taylor rule.

Indeed, the traditional Taylor rule, formally close to them, do not claim to provide a norm delivering a benchmark interest rate founded in theory but rather to describe in a synthetic way, how the central bank react to 
some economic variable fluctuations during a period. These variables are uppermost inflation deviation and output gap. However, other variables are turned out to be relevant such as one lag interest rate, the exchange rate, and the liquidity surplus. Thus in the following part, we will estimate some reaction function that have a Taylor style and we will compare them with the TTR to find the optimal reaction function

\begin{tabular}{cccccc} 
& \multicolumn{2}{c}{ Estimation Table } & Rule5 & Rule6 \\
\hline \hline Cst & Rule1 & Rule2 & Rule 4 & Rule \\
$\rho$ & - & $4.02^{* *}$ & 1.026 & - & - \\
$a_{\pi}$ & - & - & 0.76 & $0.79^{* *}$ & $0.59^{* *}$ \\
$a_{Y}$ & $0.77^{* *}$ & $1.34^{* *}$ & $0.32^{*}$ & $0.32^{* *}$ & $1.2^{* *}$ \\
$a_{e}$ & $0.23^{* *}$ & $0.18^{*}$ & $0.14^{*}$ & $0.14^{*}$ & $0.4^{* *}$ \\
\hline \hline$\overline{R^{2}}$ & & & & & 0.04 \\
DW & 0.14 & 0.57 & 0.93 & 0.83 & 0.90 \\
h-DW & 1.907 & 2.06 & 1.8 & - & - \\
SCR & - & - & & 0.26 & 1.35 \\
F-Test & 153.8 & 138.5 & 22.58 & 16.18 & 2.57 \\
AIK & - & - & 302 & - & 216 \\
SBC & 326 & 316 & 207 & 128.5 & 50 \\
\hline SBC & 330 & 323 & 216 & 134 & 62 \\
\hline \hline
\end{tabular}

**: 5\% signification level

*: $10 \%$ signification level

The tabulate value of Fisher test (F-test) is at 5\%

\section{2- $\quad$ Estimation Of Taylor Type Reaction Function}

In the last estimation, we observe a weak explanatory power for the TTR and we consider it as the cause for the omission of some key variables. That's why in this section; we try to verify the hypothesis that the RBNZ adopted a smoothing interest rate policy. To verify this hypothesis, we estimate two reaction functions; First, The static reaction function, which doesn't include the lags of interest rate as explanatory variable, then a dynamic version that will include it. The objective is to compare these two functions and to choose the optimal function according to some statistic test like F-Fisher or the Akaike and Schwarz criteria.

\section{a- $\quad$ Estimation Of The Static Reaction Function}

The static reaction function is almost a traditional Taylor rule but in a developed version. Otherwise, it comes from the Traditional Taylor rule with conventional parameters. To estimate this specification, we adopt the idea of Gerdesmeier and Roffia (2003) applied to the euro area and to New Zealand by Huang, Margaritis and Mayes (2000), which consist in writing the rule [1] as a function of realizable variables as follows:

$$
i_{t}=a_{\mathrm{O}}+a_{\pi} \pi_{t}+a_{y} Y_{g}+\varepsilon_{t}
$$

where $a_{0}:$ is a constant given by $a_{0}=\left(\bar{i}-a_{\pi} \bar{\pi}\right), a_{\pi}=(1+\alpha)$ : Actual inflation rate coefficient.

$a_{Y}=\beta:$ Output gap coefficient.

The method of estimation is the AR1 regression because we find a correlation between variables of order 1 . The Hausman test shows that all variable are exogenous. Then, the ADF test shows that all variables are stationary. 
The result (rule 2 of estimation table) shows that the inflation rate coefficient is equal to 1.35 . An inflation rate higher than one implies that the interest rate must increase when inflation increases. This phenomenon exerts a stabilisation effect on inflation, which reaches to a contracyclical monetary policy. To compare rule 1 to rule we cannot use the Fisher's test because the models 1 and 2 aren't stacked. Then we apply the information criteria of Akaike and Schwarz. These criteria, show that rule 2 is more perfectly that the one. Then, we retain this second model as the model that reflects the behavior of RBNZ better than the Traditional Taylor rule. Thereby, it is the first result in this paper that the TTR didn't the best rule for all the central bank to conducts inflation-targeting policy.

Our results are similar to those of Huang, Margaritis and Mayes (2000) who estimated the same reaction function of New Zealand during the period from 1990 to 1998. They lead to a significant inflation rate coefficient equal to 1.32 and 0.13 for output gap coefficient. The last coefficient is not statistically significant and they reach to constant interest rate, almost equal to 5. These results confirm the assumption that New Zealand adopts an inflation targeting policy with a weak output gap weight, which is coherent with the objective policies fixed by the policy maker.

In spite of the equation 2 is more useful than the TTR, we think that's not the best rule that reflects the NZRB behaviors. This conclusion is the interpretation of non-signification of output gap. We think so, to the lack of some key variables. We can justify our intuition by the weak value of the adjustment determination factor. This can be really explained by the omission of some key variables that provide more additional information and a better explanation of the interest rate evolution. Then, in the following step, we will estimate a dynamic reaction function that consists in introducing an additional explanatory variable, which is the one lags interest rate. The purpose of this idea is to see whether the RBNZ adjusts gradually its interest rate to ensure an economic stability.

\section{3- $\quad$ Estimation Of The Dynamic Reaction Function}

The objective of this section is to determine whether the RBNZ adopts a partial adjustment of its interest rate like the FED. To do so, we will introduce the one lag interest rate as an additional variable. The dynamic reaction function with smoothing interest rate is given by:

$$
R_{t}=\rho R_{t-1}+(1-\rho)\left[R^{*}+\pi_{t}+\alpha\left(\pi-\pi^{*}\right)+\beta\left(Y-Y^{*}\right)\right]+u_{t}
$$

The smoothing interest rate is an adjustment of the Taylor rule, which was adopted by Clarida, Gali and Gertler (1999) and applied to German and by Verdelhan (2001) who applied it to the euro area. Theoretically Woodford (2003), in a simple framework model, which takes account of optimist behavior of private agents, shows that some inertial degree of interest rate could be optimal. Practically, the adoption of a smoothing interest rate given by the central bank can be explained by its objective to preserve its credibility that allows us to avoid very strong official market interest rate volatility or to limit the impact on the long-term rates. Therefore, the smoothing behavior has been explained by the tendency of the central bank to smooth the variation of its interest rate in order to avoid its instability, which can affect the confidence of the economic agents. Thus, the role of the gradual adjustment interest rate lies in increasing the economic stability and ensuring some credibility on its monetary policy. The reaction function is then described in terms of a partial adjustment interest rate. This adjustment has been done to the weighed average of the expected interest rate at each period and the interest rate realized in the last period. To estimate this reaction function we adopt methodologies of Gerdesmeier and Roffia (2003) in the euro area and Huang, Margaritis and Mayes (2000) in New Zealand. The function is written as follows:

$$
i_{t}=a_{\mathrm{O}}+\rho i_{t-1}+a_{\pi} \pi_{t}+a_{y} Y_{g}+u_{t}
$$

where $a_{0}:$ Constant $a_{0}=\left[\left(r^{*}+\pi\right)-a_{\pi} \pi^{*}\right], a_{\pi}=(1-\rho) \alpha, a_{Y}=(1-\rho) \beta$.

$\rho:$ Partial adjustment coefficient of the interest rate $0<\rho<1$. 
We use the Beach MacKinnon method to resolve the autocorrelation problem of order one. The ADF test shows that all variables are stationary. The Hausman test shows that the variables in the rule are exogenous.

In all dynamic models it is not the statistic of DW that judges the autocorrelation but it's the h-DW statistics that is more efficient in this case. It is equal to: $\left.\left.h=\rho^{\wedge} \sqrt{\left[n /\left(1-n \sigma_{i t}^{2}\right.\right.}\right)\right]$

With $\rho^{\wedge}=1-d w / 2 ; n$ : observations number; $\sigma_{i t}^{2}$ : estimated variance coefficient.

In our case, we obtain an h-Durbin statistic equal to zero because $n \sigma_{i t}^{2}>1$. Then, we do not determine this statistic. According to Bourbonnais (2002), in this case we can use the DW statistic to conclude whether there is a significant serial correlation or not. Our regression gives a DW equal to 1.8. Thus, we conclude that there is no serial correlation.

It is clear that the dynamic model differs from the static model. Indeed, we find a significant and higher partial adjustment interest rate coefficient that is equal to 0.76 . According to the economic literature, this coefficient is around 0.8 in the case of New Zealand. Then, we apply a statistic test to see whether it is equal to 0.8 or not. The result of this test is as follows: $F(1,59)=0.26429$ with a significance level at 0.60911167 . Then, we can conclude that the partial adjustment interest rate coefficient is statistically equal to 0.8

However the output gap is equal to 0.10 and is statistically significant (with the threshold of $10 \%$ ). This suggests that the real production has an important role in monetary policies. Whereas, inflation rate coefficient is equal to 0.24 and is statistically significant with the threshold of $10 \%$. We always, reach higher inflation rate coefficient than that of the output gap in the case of New Zealand. Therefore, New Zealand leads an inflation targeting policy with a relatively weak weight to the real production. Our results confirm the priority to objective of price stability without neglecting the economic stability.

The adjustment determination coefficient, for this estimation, is better to the one of static model. It has been increased from 0.6 to 0.93 . This can be explained by the inclusion of the interest rate lags as an explanatory variable. The criterion of maximization of adjustment determination coefficient consists in retaining the model having the highest value. But, it has some disadvantages. It does not arbitrate between the losses of freedom degrees model and the adjustment resulting from it. To resolve this problem, we can apply the Fisher test and the information criteria Akaike or/and Schwarz.

According to the result, in row 11, we must retain the dynamic model. This rule is better that the last. So, we show an inflation coefficient equal to 0.32 and output cap coefficient equal to 0.14 . It is clear so, that NZRB accords more preoccupation for the price stability than the objective of economic stability. In addition, we show that the NZRB adopt a policy of smoothing interest rate, which is justified by the policy target agreement (PTA) in New Zealand and in the economic literature. But, in this estimation we have a problem; a weak significance of actual inflation rate and output gap coefficients, which conduct us to think that it is not the best timing that must be adopted in the function. We think also about the hypothesis of omission of some key variables that provides additional information.

Our results confirm those of Huang, Margaritis and Mayes (2000). They find a significant and higher smoothing interest rate that is equal to 0.75 (in our case: 0.766). Moreover, they find a significant output gap coefficient equal to 0.2 (in our case: 0.14 ) and an inflation rate coefficient equal to 0.37 (in our case 0.32 ). Mayes (2000a) shows, in the case of New Zealand, that it is not a surprise to find a lower output gap coefficient than that of Taylor (1993a). In Fact, the FED fixes a duality in its objective between the price stability and economic stability, whereas the RBNZ accords more priority to price stability. Moreover, we show that the RBNZ adopts the smoothing interest rate policy that's not suggested by Taylor (1993a). Thereby, the RBNZ doesn't modify dramatically its policy to any inflation and output gap variation. In this point of analysis, we retain the dynamic model, which represents better the RBNZ's behaviors than the statistic one. But the weak significance of actual inflation rate and 
output gap coefficient urges us to think that either we omit another key variable or rather, it is not the best timing of these variables to be adopted in function. Indeed, some new literature criticizes this rule.

\section{4- $\quad$ Forward-Looking Monetary Policy And The Exchange Rate Effect}

In the last subsection, we have confirmed the assumption that the RBNZ adjusted gradually its interest rate to ensure an economic stability and to reflect credibility in its monetary policy. Thus, this reaction function has been considered as the best rule that reflects the RBNZ's behaviors. However, some economists have criticized it. McCallum (1993) suggests that they aren't operational because they need information that policies-makers did not dispose actually. Mayes (2000 b) criticizes also these functions because they imply that we link information we did not have. Also, he suggests that the Forward-Looking rule can provide additional information about future economic developments. Thus, according to these economists, it is not optimal to follow this type of rule. To make them realizable and effective, the majority of researchers and economists suggest replacing these variables by their expected values. This makes it possible to link available information. These criticisms on using the actual inflation rate and the actual output gap lead to new researches that contribute to the emergence of a forward looking rule. In this context, Dennis (2003) presents a study that tries to determine the optimal reaction function. He adopts a microeconomic model to reflect the characteristics of developed countries and he limits his application to the small emergent markets. Several economists, such as Lubick and Shorfheide (2005) adopted this model applied to News Zealand, Canada, England and Australia, also by Gali and Monacelli (2005) and by Caputo and Liendo (2005) applied it in the case of Chile.

Thus, the Forward-Looking reaction function we try to estimate must include the following variables: expected inflation rate and expected output gap. However, the similar studies envisaged above, adopt a function including only the expected inflation rate and actual output gap. This can be explained by the fact that the timing of these two variables depends to the objective of policies-makers. In a recent contribution, Levin and al. (2003) suggest a rule that takes into account the expected inflation rate in one-year horizon and the actual output gap constitutes an effective and robust response to "uncertainty related to model building". The explanation for this conclusion is as follows: "we can show that such rules are then optimal for a central bank that has a quadratic loss function (i.e. which seeks to minimize the sum of the variances for its two variables: the inflation rate and the output gap). However, the output gap, in this analysis case is not considered as the deviation of the gross domestic product from its long-term tendency, but it is understood as the deviation of the gross domestic product from a level which is reached when the prices and the wages are perfectly flexible and not like the variation with a long-term tendency".

a-

Forward Looking Monetary Policy Estimation

In our analysis, we adopt this idea and we provide another justification to the fact that the RBNZ accords more priority to the price stability that is considered as its long-term objective. The Forward-Looking reaction function, we are trying to estimate, is the same one adopted by Lubick and Shorfheide (2005) in the case of industrialized countries such as the New Zealand, Canada, England and Australia. It is given by:

$$
R_{t}=\rho * R_{t-1}+(1-\rho) *\left[\omega_{1} E\left(\pi_{(t+1)}+\omega_{2}(Y-\bar{Y})\right]+\varepsilon_{t}\right.
$$

Generally, the central banks do not announce their inflation expectation. Since 1995, the RBNZ has started making these announcements. This data is stationary by carrying out the ADF test. These results show that all the variables are significant (in threshold of 10\%). The estimated model reaches to very significant $\rho$ that is equal to 0.8 . This is confirmed by economic literature, which notes that New Zealand adopts a smoothing interest rate policy equal to 0.8 . Moreover, the results note that the expected inflation rate coefficient is higher than the output gap one. This as well confirms the behaviors of the RBNZ, which gives a priority to its objective of price stability than that of economic stability. Other statistics allow us to retain the Forward-Looking rule than the backward looking such as the Akaike and Schwarz criteria. It is important to indicate that the Forward looking reaction function is the model that minimizes these criteria rather than other specifications, which are estimated above. At this point of our analysis, the best model that reflects the RBNZ's behavior is the Forward-Looking model. But we remark that the 
expected inflation coefficient is equal to $0.4(0.4=0.32 / 0.8)$ which is lower than 1 , however we expect to an inflation rate coefficient that is higher than one. This can be the result of some missed key variables in the model such as the exchange rate fluctuation that provides additional information on the future inflation path.

\section{5- $\quad$ Exchange Rate Effect On The Inflation Targeting Policy}

Taylor (2000) is interested in some transmission channels that can affect the monetary policy. In his paper, he studies three types of transmission channels: Effects of different financial market price views, then he refers to credit channel effect and finally, the exchange rate effect. Taylor concludes that only the last channel can affect the monetary policy choice, then he focuses more on the exchange rate channel. The reason that makes it more interesting is its contribution to affect the price. Moreover, it is one of the determinants of the inflation rate and the exports level. Through this channel, the variation in the foreign prices goods has been transmitted to domestic prices goods. Moreover, there is a relation between the exchange rate and the interest rate through the capital market. In his paper, Taylor makes simulations to nine monetary policy models, of open economies, to see whether some transmission channels improve the performance of some rules. He concludes that some models are more powerful and for some other, the performance is deteriorated. He shows that the difference in these models is not due to the various transmission channels but it is the result of different Forward-Looking degrees. For the majority of the developed countries, Taylor proved that the monetary transmission mechanisms have a weakly direct effect on the monetary policy choice. As for the exchange rate, Taylor concludes that it amplifies the interest rate effect but it does not affect its direction. He deduces that the direct exchange rate channel has a weakly effect on monetary policy.

In another study, Taylor (2001) suggests that the exchange rate is an important variable (Taylor (2000) proves that the exchange rate has a weak direct effect on monetary policy). The objective of his recent study is to determine if the monetary policy instrument must respond to the exchange rate fluctuation or it is sufficient to react to the domestic indicators such as inflation and the real output. In this study, Taylor concludes that the monetary policies, which directly react to the exchange rate fluctuation, do not reach a good inflation and economic stabilization. In some cases these types of rules are less powerful than other that didn't react directly to the exchange rate fluctuation. The most important conclusion in his study is the existence of indirect exchange rate channel, which affects the monetary policy in the absence of a direct channel. The inertial transmission channel combined with rational expectation causes this indirect effect, which has some advantages comparing the direct effect. The indirect exchange rate effect results from no expected or unpredictable interest rate fluctuation.

Taylor (2000) shows that the indirect channel of the exchange rate has an impact on the monetary policy in the absence of a direct channel. In this case, when the direct exchange rate effect does not exist, the interest rate reacts only to inflation and the output. Then, if the inflation rate or the output decreases (increase) in the future then the interest rate decreases (increase) in the future. For the opened economies, an appreciation of the exchange rate has two effects:

- $\quad$ Reduction in the output by the substitution effect.

- The inflation decreases because the imported price goods decrease, which causes the decrease in the output.

This last effect can cause a decrease in inflation.

Thus, these effects on inflation and the output will not take place instantaneously (at the time of the appreciation) but with a lag. This is the inertial of the monetary policy transmission mechanism. Indeed, these lags imply that, in the future, an appreciation of exchange rate decreases the future inflation rate and the output. This is equivalent to the act of an actual appreciation exchange rate, which increases the probability that the central bank will decrease its future interest rate. With rational expectation, the expected fall of the future interest rate will tend to decrease the actual interest rate. Thus, the exchange rate channel appreciation plays an important role in monetary policy if it is based on expected inflation and output. Taylor, among the pioneers, studied the effect of the exchange rate channel on the monetary policy. Indeed, this variable includes additional information on the future inflation rate 
path that's not necessarily captured by actual inflation rate or the output gap. Moreover, it provides a key indicator on the economy state more than to refer only to the interest rate.

Lubik and Shorfheide (2005) show that the RBNZ, Australian and England central bank do not explicitly respond to the exchange rate fluctuation. Whereas, the central bank of Canada takes account this variable in its monetary policy. That's why in this part; we added in the last function a new variable of the exchange rate fluctuation. The estimation of this function can determine if New Zealand monetary policy responds directly or explicitly to the exchange rate fluctuation or only the indirect effect of the exchange rate channel has an effect on this monetary policy like the case showed by Taylor (2001) on United States (example of the developed countries) In this section, we adopt the reaction function presented by Lubik and Shorfheide (2005) that is given by:

$i_{t}=\rho R_{t-1}+(1-\rho)\left[\omega_{\pi} \pi_{t}+\omega_{Y} \beta\left(Y_{t}-\bar{Y}\right)+\omega_{e}\left(e_{t}-e_{t-1}\right)\right]+\rho * i_{t-1}+\varepsilon_{t}$

To estimate this equation, we write it as follows: $i_{t}=\rho R_{t-1}+\alpha \pi_{t}+\beta\left(Y_{t}-\bar{Y}\right)+\gamma \Delta e_{t}+\varepsilon_{t}$

where $\alpha=(1-\rho) \omega_{\pi} ; \beta=(1-\rho) \omega_{Y} ; \gamma=(1-\rho) \omega_{e}$

We apply the generalized moments method (GMM) to estimate this function. The Hausman test shows the exogeneity of the exchange rate fluctuation. The application of this method requires an effective choice of the instrumental variables that must satisfy the orthogonalities conditions. To realize the best choice for these instruments, we refer to the literature that estimates this type of function. Gerdesmeier and Roffia (2003) estimate this type of function for the euro area. Then, they adopt 4 to 6 lags of the explanatory variable like instruments. Their choice is being adopted with reference to the Taylor rule.

The estimated results show that the exchange rate fluctuation coefficient is very low (0.04) and not significant. We conclude that RBNZ does not answer explicitly to the exchange rate fluctuation. Therefore, we can say that the direct exchange rate channel effect does not have any effect on monetary policy instrument. Our result confirms those of Lubik and Schorfheide (2005), who conclude that the RBNZ does not response explicitly to the exchange rate fluctuation. They find a weak exchange rate fluctuation coefficient equal to 0.04 . Whereas, in our result the statistic that determines the optimal model to retain require keeping this last function as the optimal rule that describes the behavior of the RBNZ. In spite of the insignificativity of the exchange rate fluctuation, the optimal rule must incorporate this variable. Therefore, we cannot omit it in the reaction function.

This result can be explained easily. Indeed, the direct effects are the immediate impact that an exchange rate has on the prices of tradable goods. Whereas, the indirect effects out of the way in which changes in the exchange rate affect the demand for goods and services product locally. According to these definitions, the relative importance of direct exchange rate pass-through from exchange rate movements to condition prices index inflation is highly dependent. This is the case of New Zealand before adopting the inflation targeting policy, during the 1970s and 1980s, when the exchange rate is the anchored variable and not the price level (Brook 1998). Then, since the 1990s, the period of achievement of price stability is matched by flattening out in the nominal exchange rate trend. In this period of price level anchoring, the direct effect of the exchange rate pass-through has gradually fallen over time. This was be shown by Hampton (2001). In addition, the development of financial markets and greatly availability of hedging contracts may help to explain the fall of the pass-through. That's why, currently, many researches give more preoccupation, to the indirect effect of the exchange rate changes. Svenson's (1999) simulations of a small open economy model are directly relevant to this question; he reports that the benchmark rule (without the exchange rate terms) performs well in reducing the variability of inflation around the inflation target and output around its potential level. In assessing these results with the benchmark rule Svenson (1999) concludes that the rule "appears somewhat robust; perhaps surprisingly robust". Then, Svenson (1999) concludes that no better rule exists. The main point is that even a small open economy view of the monetary transmission mechanism does not change the assessment that the simple benchmark rule responding systematically only to inflation and output works well and is robust. 
Our results confirm the Taylor's conclusion (2001), which says that the indirect effect carries on the direct effect. Taylor explains the last finding of Svenson (1999) as follows: the exchange rate channel effectively makes a connection from the interest rate to aggregate spending. Rather than simply changing the real interest rate, a change in monetary policy changes the real exchange rate as well. The exchange rate magnifies the real interest rate effect, but does not affect its direction. Hence, a reaction of the policy rule only to inflation and output works just fine in stabilizing the output and inflation.

Our results conduct us to retain the assumption of the presence of the indirect effect of the exchange rate because we find that a no significativity of this variable implies the absence of this direct exchange rate channel. But, if we refer to Fisher test and Akaike and Schwarz criteria (see the row of rule 6 in the estimation Table), this model is the model that minimizes more these criteria. Then, we conclude to retain this model as the optimal model or optimal reaction function that reflects the RBNZ behavior. Then, because we retain this model, which includes the exchange rate fluctuation, and because of the absence of the direct effect of the exchange rate, we can strongly retain the idea of the presence of the indirect channel of the exchange rate. Moreover, economically, this variable provides additional information on the future inflation path and the output, which is not captured by current inflation, and output. Indeed, in 1998 the RBNZ had adopted the monetary condition index (MCI) as the monetary policy instrument during the period form 1996 to 1998. This reflects the desire of the RBNZ to take into account of the exchange rate in its policy.

According to Mayes (2000 a), the monetary policy is a wrong science; errors are inevitable, beheld uncertainty on the mechanisms through it the economy operates, the shocks that can occurs and the economic capacity to neutralize them. Thus, in a future study, we can take into account the possibilities of asymmetric data. In second step we can determine, initially, the indirect exchange rate channel by the pass-through effect. We can adopt a microeconomic model that distinguishes between domestic and foreign goods.

\section{CONCLUSION}

To find the best rule, many researches adopted some methodologies that differ from ours. In this paper, we propose a descriptive analysis to determine the optimal monetary policy that reflects the behavior of the RBNZ. Indeed. We adopt a gradual approach that consists in starting from the Traditional Taylor rule and after that including some extensions to find the optimal rule. In the first part we estimated the TTR and we conclude that this rule reflects the behavior of the RBNZ but it has a weak explication power. Thus, can be the consequence of some key variables omission. That's why, in the second part we introduce some variables indicated by the economic literature like the one lags of interest rate as an additional explanation variable. So, at this step, we estimate a Taylor style rule and not the TTR. In this point of analysis, we conclude that the RBNZ follows a Taylor style rule to conduct its monetary policy of inflation targeting. So, as the first result, we show that the TTR didn't follow by the RBNZ to conducts its monetary policy under inflation targeting. In addition, it adopts a smoothing interest rate policy to reflect some credibility and stability.

Beheld the criticism to these type of rule, which use the actual inflation and output data, we estimate a new Taylor style rule; it's the Forward-Looking rule. The results show that this is the more better that the last. The last hypothesis to verify is the presence of the exchange rate in the monetary policy instrument. In other word, we tested if the RBNZ react to the exchange rate deviation in the case of inflation targeting. We show that the RBNZ didn't react to the exchange rate deviation from the direct channel but it there was dependence from the indirect channel. Indeed, our results find that when we include the exchange rate deviation variable in the rule, we find a coefficient equal to 0.04 but non significant. But when we compare this rule to the last one (that not include an exchange rate variable as explanatory variable), the statistics values show that we must return the rule that includes the exchange rate.

So, this paper gives the rule followed by the NZRB to conduct its monetary policy. This rule is an extension of the TTR named style Taylor rule. In other word, it is not the TTR that must be adopted in all cases of inflation targeting. In other part, we show that is a Forward6Looking rule that must be adopted with a smoothing interest rate. 
As a final result and more important is the inclusion of the exchange rate deviation in the rule. This is was the debate of the literature.

Our study provides some limits, we have supposed the linearity of the reaction function but this type of specification can be not linear. Some authors study this problem actually. In future study, we propose to analyse the role of the exchange rate under inflation targeting policy and to check the indirect and the direct exchange rate channel. In other word, it is useful to justify the role of the exchange rate in this type of rule.

\section{BIBLIOGRAPHY}

1. Barro R.J., Gorden D.B., (1983) Rule, discretion and reputation in a model of monetary policy, Journal of Monetary Economics, 12, 101-121.

2. Ball, L. (1999) Policy Rules for Open Economies, in John B. Taylor (ed.) Monetary Policy Rules, University of Chicago Press, 1999.

3. Brooks.R (1998), Inflation and Monetary Policy Reform, in Australia: Benefiting from Economic Reform, International Monetary Fund, pp. 63-94

4. Caputo, R., Liendo, F (2005). Monetary Policy, Exchange Rate and Inflation Inertia in Chile: A Structural Approach Working Paper, Central bank of Chile, WP/352/2OO5.

5. Clarida, R., Gali, J., Gertler, M. (1999). Monetary Policy Rules in Practice: Some International Evidence, European Economic Review, June. pp.1033-67.

6. Dennis, Richard (2003). Exploring the Role of the Real Exchange Rate in Australian Monetary Policy. The Economic Record, 79 (2), 20-38.

7. Gali, J. and Monacelli, T. (2005). Monetary Policy and Exchange Rate Volatility in a Small Open Economy, Review of Economics Studies 72, pp 707-734.

8. Gerdesmeier, D., Roffia, B. (2003) Empirical estimate of reaction function for the euro area, European Central Bank, Working paper $\mathrm{N}^{\circ} 206 / 03$.

9. Hampton, T. (2001) How much do import price shocks matter for consumer prices? Reserve Bank of New Zealand Discussion Paper 01/06.

10. Huang, A., Margaritis, D., Mayes, D. (2000). Monetary Policy Rule in Practice: Evidence from New Zealand, Discussion paper 18/01, Research Department, Central Bank of Finland, 21, 9, 2001.

11. Kozicki, S. (1999). How Useful Are Taylor Rules for Monetary Policy, Economic Review, Federal Reserve Bank of Kansas City, second quarter.

12. Lubik, T. and F.Schorfheide (2005). Do Central Banks Respond to Exchange Rate Fluctuations? A Structural Investigation, Mimeo University of Pennsylvania.

13. Levin A., Wieland V., Williams J. 2003. The performance of forecast-based monetary policy rules under model uncertainty, American Economic Review, Vol. 93 № 3, June, pp. 622-45.

14. Mayes, D.G. (2000a). The Operation of Monetary Policy in New Zealand, Evidence submitted to the Review of Monetary Policy, New Zealand Treasury.

15. Mayes, D.G. (2000b) Evidence submitted to the Review of Monetary Policy, New Zealand Treasury.

16. McCallum, B.T. (1993). Discretion Versus Policy Rule in Practice: Two Critical Points A Comment, Carnegie-Rochester Conference Series on Public Policy, 39, December, 215-220.

17. Obstfeld, Maurice and Kenneth Rogoff (1995). Exchange Rate Dynamics Reduce. Journal of Political Economy, 103, 624-660.

18. Orphanides, A. (1997). Monetary Policy Rule Based on Real Time Data, Board of Governors of the Federal Reserve System, December.

19. Plantier, C-L., Scrimgeours, D. Estimating Taylor rule for New Zealand with time varying neutral real rate, Reserve Bank for New Zealand, Discussion Paper DP 2002/06.

20. Smeets, F. (1998). Output Gap Uncertainty: Does It Matter For the Taylor Rule, BIS Working Paper, NO/ 60-Novembre 1998.

21. Svensson, L. (1997). Inflation Forecast Targeting: Implementing and Monitoring Inflation Targets, European Economic Review, (41) pp.1111-1146.

22. Svensson.L (1999), Inflation Targeting as a Monetary Policy Rule, Journal of Monetary Economics, vol. 43, pp. 607-654. 4.3 
23. Svensson, L. (2000). Open-Economy Inflation Targeting, Journal of International Economics, February, 655-79.

24. Taylor, J.B. (1993a). Macro economic policy in World economy: From econometric design to practical operation, New York: W.W. Norton.

25. Taylor, J.B. (1993b). Discretion versus Policy Rules in Practice, Carnegie-Rochester Conference Series on Public Policy, 39, 195-214.

26. Taylor, John. (1999). A Historical Analysis of Monetary Policy Rules, In Monetary Policy Rules. Ed. John Taylor. Chicago: University of Chicago Press.

27. Taylor, JB. (2000). Alternative Views of the monetary Transmission Mechanism: What difference Do they Make for Monetary Policy, The Oxford Review of Economic Policy, revised and shortened version of an earlier paper entitled, The Monetary Transmission Mechanism and the Evaluation of Monetary Policy Rules, presented par the Central bank of Chile in September, 20-21, 1999.

28. Taylor, J. (2001). The Role of the Exchange Rate in Monetary-Policy Rules, American Economic Review. May. pp 263-67.

29. Woodford, M., 2003. Interest and prices: foundations of a theory of monetary policy, Princeton University Press.

\section{NOTES}

